\title{
ANALISIS FAKTOR-FAKTOR YANG MEMPENGARUHI STUNTING PADA BALITA DI KOTA GORONTALO MENGGUNAKAN REGRESI BINOMIAL NEGATIF
}

\author{
Fahrezal Zubedi ${ }^{1}$, Muftih Alwi Aliu', Yolanda Rahim ${ }^{3}$, Franky Alfrits Oroh ${ }^{4}$ \\ ${ }^{1,2,3}$ Program Studi Statistika, Fakultas MIPA, Universitas Negeri Gorontalo \\ ${ }^{4}$ Program Studi Pendidikan Matematika, Fakultas MIPA, Universitas Negeri Gorontalo \\ e-mail: fahrezal@ung.ac.id
}

\begin{abstract}
Abstrak
Penelitian ini bertujuan untuk memodelkan kasus stunting pada balita di kota Gorontalo tahun 2018 menggunakan Regresi Binomial Negatif. Pada model tersebut, dapat diketahui faktor-faktor signifikan yang mempengaruhi kasus stunting pada balita di kota Gorontalo tahun 2018. Penelitian ini menggunakan data kasus stunting di 9 (Sembilan) kecamatan di kota Gorontalo dan faktorfaktor yang mempengaruhinya. Data penelitian diperoleh dari Dinas Kesehatan Kota Gorontalo. Penelitian ini mengunakan satu variabel respon yaitu Banyaknya Kasus Stunting dan empat variabel prediktor yaitu Jumlah Balita yang mendapatkan Asi Eksklusif, Persentase Berat Badan Lahir Rendah (BBLR), Persentase Balita yang mendapatakan Imunisasi Dasar Lengkap, dan Jumlah Sanitasi Layak. Hasil Penelitian yang diperoleh adalah variabel Jumlah balita yang mendapatkan asi eksklusif dan persentase balita yang mendapatkan imunisasi dasar lengkap yang berpengaruh secara signifikan terhadap kasus stunting pada balita di kota Gorontalo tahun 2018. Hal ini ditunjukan dengan nilai $P$-value variabel balita yang mendapatkan asi eksklusif sebesar 0,00283 dan nilai $P$-value variabel balita yang mendapatkan imunisasi dasar lengkap sebesar 0,06564 .
\end{abstract}

Kata Kunci: Stunting; Regresi Binomial Negatif

\begin{abstract}
This study aims to model stunting cases in children under five in Gorontalo city in 2018. In this model, it can be seen that the significant factors that affect stunting cases in children under five in Gorontalo city in 2018. This study uses data on stunting cases in 9 (nine) districts in the city of Gorontalo and the factors that influence it. The research data were obtained from the Public Health in Gorontalo city. This study used one response variable, namely the number of cases of stunting and four predictor variables, namely number of toddlers who received exclusive breastfeeding, the percentage of low birth weight $(L B W)$, the percentage toddlers who received complete basic immunization, and number of proper sanitation. The results obtained were the variables of number of toddlers who received exclusive breastfeeding and the percentage toddlers who received complete basic immunization which had a significant effect on stunting cases in children under five in the city of Gorontalo in 2018. This was indicated by the P-value of the variable for number of toddlers who received exclusive breastfeeding of 0.00283 and $P$-value of variable the percentage toddlers who get complete basic immunization is 0.06564 .

Keywords: Stunting, Negatif Binomial Regression
\end{abstract}

\section{PENDAHULUAN}

Stunting merupakan gangguan pertumbuhan fisik yang ditandai dengan penurunan kecepatan pertumbuhan dan merupakan dampak dari ketidakseimbangan gizi (Apriluana and Fikawati 2018). Status gizi balita dapat diukur berdasarkan tiga indeks yaitu berat badan menurut umur $(\mathrm{BB} / \mathrm{U})$, tinggi badan menurut umur $(\mathrm{TB} / \mathrm{U})$, dan berat badan menurut tinggi badan (BB/TB). Stunting pada balita merupakan masalah kesehatan di Indonesia yang terbilang cukup tinggi. Gorontalo merupakan salah satu provinsi yang memiliki masalah 
stunting di Indonesia pada tahun 2018, tiga daerah di provinsi Gorontalo masih tinggi angka stunting yaitu Kota Gorontalo, Kabupaten Boalemo dan Kabupaten Gorontalo Utara. Prevalensi stunting di Kota Gorontalo tahun 2018 sebesar 28,2 persen. Menurut profil kesehatan tahun 2018 persentase stunting tertinggi dicapai oleh Kota Tengah sebesar 41,3\% dan persetase terendah dicapai oleh Dungingi sebesar 14,9 \% (Profil Kesehatan, 2018).

Jumlah stunting di Kota Gorontalo merupakan data yang bertipe diskrit dan non negatif. Analisis yang cocok digunakan untuk tipe data seperti ini adalah Regresi Poisson. Model Regresi Poisson berasal dari distribusi Poisson. Dalam model Regresi Poisson asumsi yang harus dipenuhi adalah ekuidispersi. Asumsi ekuidispersi jarang terjadi pada tipe data diskrit. Pada data diskrit sering mengalami kasus overdispersion (penyimpangan tinggi) yaitu nilai mean dan variance tidak sama atau dengan kata lain nilai variance lebih besar daripada nilai mean (Utami 2013). Jika tetap menggunakan Regresi Poisson akan mengakibatkan dugaan dari parameter koefisien regresinya tetap konsisten tetapi tidak efisien. Hal ini berdampak pada nilai standar eror yang menjadi underestimate, sehingga kesimpulannya menjadi tidak valid. Beberapa penelitian yang terkait dengan penyelesaian masalah overdispersion diantaranya adalah model regresi generalized poisson (Mahfudhotin 2020) dan regresi binomial negatif (Sauddin et al. 2020). Menurut penelitian (Prahutama et al. 2017) bahwa salah satu pilihan yang terbaik adalah menggunakan regresi binomial negatif. Oleh karena itu, analisis regresi yang cocok untuk mengatasi overdispersi pada Regresi Poisson adalah Regresi Binomial Negatif.

Regresi Binomial Negatif adalah salah satu cara untuk memodelkan data cacah yang berkondisi ekuidispersi maupun overdispersi. Dalam estimasi parameter model regresi Binomial negatif dapat menggunakan metode maximum likelihood estimation (MLE) (Keswari et al., 2014). Tujuan dari penelitian ini yaitu memodelkan kasus stunting pada balita di kota Gorontalo tahun 2018 dan juga untuk mengetahui faktor-faktor signifikan yang mempengaruhi stunting pada balita di kota Gorontalo dengan menggunakan Regresi Binomial Negatif.

\section{METODE PENELITIAN}

\subsection{Data}

Penelitian ini mengunakan data sekunder yang diperoleh dari Dinas Kesehatan Kota Gorontalo. Data yang digunakan yaitu banyaknya kasus Stunting di sembilan kecamatan yang ada di Kota Gorontalo dan faktor-faktor yang mempengaruhinya pada bulan Januari 2018 sampai dengan Desember 2018. Data penelitian disajikan pada Tabel 1.

Tabel 1. Data Penelitian

\begin{tabular}{cccccc}
\hline Kecamatan & $\boldsymbol{y}$ & $\boldsymbol{x}_{\mathbf{1}}$ & $\boldsymbol{x}_{\mathbf{2}}$ & $\boldsymbol{x}_{\mathbf{3}}$ & $\boldsymbol{x}_{\mathbf{4}}$ \\
\hline Kota Barat & 13 & 145 & 3,65 & 84,9 & 5515 \\
\hline Dungingi & 7 & 104 & 1,7 & 88,4 & 6444 \\
\hline Kota Selatan & 12 & 69 & 4,8 & 90,5 & 5058 \\
\hline Kota Timur & 27 & 204 & 3 & 93,8 & 7218 \\
\hline Hulonthalangi & 13 & 140 & 5,8 & 82,2 & 3624 \\
\hline Dumbo Raya & 18 & 139 & 2,5 & 98 & 4362 \\
\hline Kota Utara & 12 & 135 & 2,7 & 81,6 & 4680 \\
\hline Kota Tengah & 24 & 220 & 1 & 91,7 & 6929 \\
\hline Sipatana & 13 & 108 & 5,8 & 90,3 & 5076
\end{tabular}

Penelitian ini mengunakan satu variabel respon dan empat variabel prediktor. Variabelvariabel yang digunakan disajikan pada Tabel 2 berikut: 
Tabel 2. Variabel Penelitian

\begin{tabular}{ccc}
\hline Variabel & $\begin{array}{c}\text { Simbol } \\
\text { Variabel }\end{array}$ & Deskripsi \\
\hline Respon & $y$ & Jumlah Stunting \\
\hline \multirow{3}{*}{ Prediktor } & $x_{1}$ & Jumlah Balita yang Mendapatkan Asi Esklusif \\
\cline { 2 - 3 } & $x_{2}$ & Persentase Berat Badan Lahir Rendah \\
& $x_{3}$ & Persentase Balita yang Mendapatkan Imunisasi Dasar \\
& $x_{4}$ & Lengkap \\
\hline
\end{tabular}

\subsection{Analisis Data}

Data dianalisis menggunakan Regresi Binomial Negatif dengan bantuan software Open Source Rstudio. Langkah-langkah analisis data sebagai berikut:

\section{a. Uji Multikolinearitas}

Multikolinearitas adalah suatu keadaan antar variabel-variabel prediktor terdapat korelasi yang tinggi. Multikolinearitas dapat berakibat pada kurang akuratnya hasil pendugaan. Untuk mendeteksi adanya multikolinearitas dapat digunakan nilai Variance Inflation Factor $(V I F)$. Rumus VIF dapat ditulis sebagai berikut :

$$
V I F=\frac{1}{1-R^{2}}
$$

dengan $\mathrm{R}^{2}$ merupakan koefisien Determinasi, jika nilai VIF lebih dari 10 maka dapat disimpulkan terjadi multikolinearitas (Amaliana et al., 2018).

\section{b. Pembentukan Model Regresi Poisson}

Regresi Poisson adalah regresi yang digunakan untuk memodelkan hubungan antar variabel respon dan variabel prediktor dimana distribusi variabel responya mengikuti Distribusi Poisson (Aulele 2012). Regresi Poisson adalah model analisis yang dapat digunakan untuk memodelkan variabel respon yang berupa data cacah (Fitrial and Fatikhurrizqi 2021). Berikut adalah pemetaan logaritma natural yang digunakan untuk memodelkan Regresi Poisson (Sma et al. 2012):

$$
g\left(\mu_{i}\right)=\ln \mu_{i}=x_{i}^{\prime} \beta
$$

Sementara model regresi Poisson dapat dituliskan sebagai berikut (Sundari 2012) :

$$
y_{i}=\exp \left(x_{i}^{\prime} \beta\right)+\varepsilon_{i}
$$

\section{c. Uji Overdispersi Model Regresi Poisson}

Pada Regresi Poisson terdapat salah satu asumsi yang harus dipenuhi untuk memodelkan Regresi Poisson. Asumsi yang harus dipenuhi adalah nilai rata-rata variabel respon memiliki nilai yang sama dengan nilai variansnya, asumsi ini disebut asumsi Ekuidispersi. Dalam beberapa penelitian seringkali asumsi Ekuidispersi tidak terpenuhi hal ini dikarenakan terdapat perbedaan nilai rata-rata dan varians pada data, kondisi ini disebut Overdispersi (Fitrial and Fatikhurrizqi 2021).

Uji statistik yang bisa juga digunakan untuk mendeteksi overdispersi pada suatu data adalah uji overdispersi yang dapat menggunakan package AER dari software RStudio (Herindrawati et al. 2017) 
Hipotesis :

$\mathrm{H}_{0}$ : Tidak Terjadi Overdispersi

$\mathrm{H}_{1}$ : Terjadi Overdispersi

Keputusan yang diambil untuk uji overdispersi menggunakan software RStudio yaitu jika $p$-value $<\alpha$ maka tolak $\mathrm{H}_{0}$ atau data mengalami overdispersi, dimana nilai $\alpha$ yang digunakan adalah 0,1 atau $10 \%$

\section{d. Pembentukan Model Regresi Binomial Negatif}

Salah satu cara untuk memodelkan data cacah yang berkondisi ekuidispersi maupun kondisi overdispersi, yaitu Regresi binomial negatif (Keswari et al., 2014). Bentuk umum dari Regresi Binomial Negatif adalah sebagai berikut (Utami 2013) :

$$
y_{i}=\exp (\boldsymbol{X} \beta)
$$

dimana $X$ merupakan variabel prediktor yang berbentuk matrix dengan ukuran $(n x(p+1))$ dan $\beta$ merupakan parameter ukuran $((p+1) x l), y$ merupakan variabel respon berdistribusi poisson yang berbentuk vector dengan ukuran $(n \times 1)$ dengan $i=1,2,3, \ldots, n$ (Casella et al., 1990). Model Regresi Binomial Negatif merupakan pemodelan nilai harapan dari variabel respon sebagai fungsi eksponensial dari sejumlah kovariat, yang bentuknya sebagai berikut:

$$
E\left(y_{i}\right)=\mu_{i}=\exp \left(\beta_{0}+\sum_{j=1}^{m} \beta_{j} x_{j}\right)
$$

Dimana $i$ merupakan unit dan $m$ menyatakan banyaknya variabel prediktor yang digunakan (Utami 2013). Fungsi kepadatan peluang dari distribusi Binomial Negatif sebagai berikut (Fitrial and Fatikhurrizqi 2021):

$$
f(y: \mu, \theta)=\frac{\Gamma(y+\theta)}{\Gamma(\theta) y !} \frac{\mu^{y} \theta^{\theta}}{(\mu+\theta)^{y+\theta}}
$$

Dimana $\mu$ sebagai rata-rata dan $\theta$ sebagai parameter dispersi serta $\Gamma($.$) merupakan fungsi$ gamma. Dalam estimasi parameter model Regresi Binomial Negatif dapat menggunakan metode maximum likelihood estimation (MLE). Tetapi hasil yang dihasilkan tidak eksplisit atau fungsi MLE tidak converge, sehingga digunakan metode iterasi Newton-Rapson (Alan Agresti 2009) .

Metode Newton-Raphson merupakan metode yang memerlukan satu titik awal (initial value) sebagai tebakan awal, memerlukan slope atau gradien pada titik tersebut, dan barisan titik potong garis singgungnya dengan sumbu-X. Jika titik awal yang dipilih nilai turunannya nol maka metode ini tidak dapat digunakan. Rumus yang dapat digunakan sebagai iterasi adalah

$$
x_{r+1}=x_{r}-\frac{f\left(x_{r}\right)}{f^{\prime}\left(x_{r}\right)} ; f^{\prime}\left(x_{r}\right) \neq 0
$$

Iterasi dapat dihentikan dengan cara mensyaratkan jarak dua titik apit hampiran akarnya sangat dekat yaitu kurang dari $\varepsilon>0$; dimana nilai $\varepsilon$ positif yang cukup kecil atau melakukan pembatasan pada banyaknya iterasi (Rochmad 2013).

\section{e. Uji Siginifikansi Model Binomial Negatif}


Pengujian parameter dilakukan untuk mengetahui pengaruh variabel prediktor terhadap variabel respon. Pengujian parameter dilakukan secara simultan dan parsial. Uji simultan bertujuan untuk melihat pengaruh variabel prediktor secara bersama-sama terhadap variabel respon (Fitrial and Fatikhurrizqi 2021), Pengujian secara serentak dilakukan menggunakan uji rasio likelihood dengan hipotesis sebagai berikut. (Dhiya 2020) :

$H_{0}: \beta_{1}=\beta_{2}=\cdots=\beta_{k}=0$

$H_{1}$ : minimal terdapat satu $\beta_{j} \neq 0$, dengan $j=1,2, \ldots, k$

Uji ini menggunakan uji rasio likelihood dengan statistik ujinya sebagai berikut (Dhiya 2020):

$$
G=-2 \ln \left[\frac{L(\widehat{\omega})}{L(\widehat{\Omega})}\right]=2 \ln L(\widehat{\Omega})-2 \ln L(\widehat{\omega})
$$

$L(\widehat{\omega})$ merupakan nilai likelihood untuk model sederhana tanpa melibatkan variabel bebas dan $L(\widehat{\Omega})$ merupakan nilai likelihood untuk model lengkap dengan melibatkan variabel bebas.

Untuk mengambil keputusan tolak $H_{0}$ dapat dilihat jika nilai $G>x_{(\alpha, v)}^{2}$, hal ini karena statistik uji $G$ mengikuti distribusi Chi-Square. Nilai v diperoleh dari banyaknya parameter dalam model. Nilai $x_{(\alpha, v)}^{2}$ dapat dilihat pada tabel Chi-Square.

Sementara untuk pengujian secara parsial dilakukan menggunakan uji Wald, dengan hipotesis sebagai berikut (Dhiya 2020) :

$$
\begin{aligned}
& H_{0}: \beta_{j}=0 \\
& H_{1}: \beta_{j} \neq 0
\end{aligned}
$$

dengan $j=1,2, \ldots, k$., dengan statistik uji Wald sebagai berikut (Dhiya 2020):

$W_{\text {hitung }}=\frac{\widehat{\beta}_{j}}{S E\left(\widehat{\beta}_{j}\right)}$

dengan $j=1,2, \ldots, k$ dan $\hat{\beta}_{j}$ adalah nilai penduga dari $\beta_{j}$, serta $S E\left(\hat{\beta}_{j}\right)$ sebagai standard error dari $\hat{\beta}_{j}$.

Keputusan yang diambil untuk uji Wald adalah tolak $H_{0}$ jika $p$-value $<\alpha$ atau menggunkan nilai $W_{\text {hitung }}$ dengan keputusan tolak $H_{0}$ jika nilai $W_{\text {hitung }}>Z_{\alpha / 2}$ atau nilai $W_{\text {hitung }}<-Z_{\alpha / 2}$, nilai $Z_{\alpha / 2}$ dapat dilihat pada tabel distribusi normal. Nilai $\alpha$ yang digunakan pada penelitian ini adalah $10 \%$.

\section{f. Menentukan model terbaik}

Akaike's Information Criterion diperkenalkan pada tahun 1973 oleh Akaike sebagai pendekatan penaksir yang tak bias dari suatu hasil pemodelan. AIC digunakan untuk melihat kecocokan model terhadap data. Model regresi terbaik adalah model regresi yang memiliki nilai $A I C$ terkecil. Nilai $A I C$ dapat dinotasikan sebagai berikut (Ramadhani et al. 2018):

$$
A I C=-2 \ln \mathrm{L}(\beta)+2 \mathrm{k}
$$

\section{HASIL DAN PEMBAHASAN}

Langkah pertama yaitu melakukan uji multikolinearitas. Untuk mendeteksi adanya multikolinearitas dapat digunakan nilai Variance Inflation Factor (VIF). Hasil Uji Multikolinearitas dapat dilihat pada Tabel 3, sebagai berikut: 
Tabel 3. Hasil Uji Multikolinearitas

\begin{tabular}{ccccc}
\hline Variabel & $\boldsymbol{x}_{\mathbf{1}}$ & $\boldsymbol{x}_{\mathbf{2}}$ & $\boldsymbol{x}_{\mathbf{3}}$ & $\boldsymbol{x}_{\mathbf{4}}$ \\
\hline $\boldsymbol{V I F}$ & 1,489335 & 1,754166 & 1,164098 & 1,887712 \\
\hline
\end{tabular}

berdasarkan Tabel 3, dapat dilihat bahwa tiap variabel prediktor tidak ada nilai VIF yang lebih dari 10. Hal ini menunjukkan tidak terjadi gejala multikolinearitas sehinga dapat dilanjutkan pada tahap memperoleh bentuk taksiran model Regresi Poisson.

Bentuk taksiran model Regresi Poisson yang diperoleh, sebagai berikut:

$$
\mu_{i}=\exp \left(-1,65+0,007832 x_{i 1}+0,07674 x_{i 2}+0,03394 x_{i 3}-0,00001656 x_{i 4}\right)
$$

Sebelum lanjut pada tahap Regresi Binomial Negatif, harus dicek apakah data tersebut terjadi Overdispersi. Pada hasil uji Overdispersi menggunkan packages AER dari software RStudionilai $p$-value $=0,06989<\alpha$, dimana nilai $\alpha$ adalah 0,1 , sehingga data penelitian mengalami Overdispersi, yang berarti model Regresi Poisson tidak cocok digunakan yang selanjutnya akan dilanjutkan pada langkah Binomial Negatif.

Pada model Binomial Negatif pertama, melibatkan semua variabel prediktor yaitu variabel $x_{1}, x_{2}, x_{3}$ dan $x_{4}$. Model pertama yang diperoleh, sebagai berikut:

$$
\mu_{i}=\exp \left(-1.625+0.007832 x_{i 2}+0.07674 x_{i 2}+0.03394 x_{i 3}-0.00001656 x_{i 4}\right)
$$

Kemudian dilanjutkan Uji Simultan dengan cara, sebagai berikut:

$2 \ln L(\widehat{\Omega})=-42,166$ (nilai tersebut didapatkan melalui program RStudio pada model tidak lengkap atau model tanpa variabel independen) dan $2 \ln L(\widehat{\omega})=-56,693$ (nilai tersebut didapatkan melalui program RStudio pada model lengkap atau model dengan variabel independen), sehingga diperoleh:

$$
\begin{aligned}
& G=-2 \ln \left[\frac{L(\widehat{\omega})}{L(\widehat{\Omega})}\right]=2 \ln L(\widehat{\Omega})-2 \ln L(\widehat{\omega}) \\
& G=-42,166-(-56,693) \\
& G=14,527
\end{aligned}
$$

Berdasarkan hasil statistik uji, diperoleh nilai $G=14,527>x_{(0,05,4)}^{2}=$ 9,4877sehingga keputusannya tolak $H_{0}$, dapat disimpulkan minimal terdapat satu variabel yang berpengaruh. Selanjutnya dilanjutkan pada tahap Uji Parsial, hasil Uji Parsial disajikan pada tabel 4 berikut:

Tabel 4. Hasil Uji Parsial

\begin{tabular}{|c|c|c|c|}
\hline Variabel & $\boldsymbol{w}_{\text {hitung }}$ & $\mathbf{Z}_{\mathbf{0 , 1 / 2}}$ & P-value \\
\hline$y$ & $-0,921$ & 1,65 & 0,35681 \\
\hline$x_{1}$ & 2,986 & 1,65 & 0,00283 \\
\hline$x_{2}$ & 1,080 & 1,65 & 0,28004 \\
\hline$x_{3}$ & 1,841 & 1,65 & 0,06564 \\
\hline
\end{tabular}




\begin{tabular}{l|l|l|l|}
$x_{4}$ & $-0,165$ & 1,65 & 0,86878 \\
\hline
\end{tabular}

Berdasarkan hasil Uji Parsial pada Tabel 4, terlihat bahwa variabel $x_{1}$ dan $x_{3}$ nilai $p$ value $<\alpha$ yang berarti tolak $H_{0}$ sedangkan variabel $x_{2}$ dan $x_{4} p$-value $>\alpha$ yang berarti terima $H_{0}$, dimana nilai $\alpha$ sebesar 0,1 atau $10 \%$. Selain itu, variabel $x_{1}$ dan $x_{3}$ memiliki nilai $W_{\text {hitung }}>Z_{0,1 / 2}$ yang artinya tolak $H_{0}$. Berdasarkan pernyatan sebelumnya, yaitu variabel yang berpegaruh signifikan hanya variabel $x_{1}$ dan $x_{3}$ sehingga variabel $x_{2}$ dan $x_{4}$ diabaikan dan dianalisis kembali untuk mendapatkan model baru tanpa variabel $x_{2}$ dan $x_{4}$. Model Regresi Binomial Negatif yang digunakan pada penelitian ini berdasarkan Tabel 4, yaitu:

$$
\mu_{i}=\exp \left(-0,665410+0.006171 x_{i 1}+0.027815 x_{i 3}\right)
$$

Model terbaik yang dihasilkan oleh model Regresi Binomial Negatif disajikan pada Tabel 5, yaitu:

Tabel 5. Hasil Akaike's Information Criterion

Model Regresi Nilai AIC

$\begin{array}{ll}\text { Binomial Negatif } & 54,166 \\ \text { Binomial Negatif dengan variabel signifikan }\left(\boldsymbol{x}_{\mathbf{1}} \text { dan } \boldsymbol{x}_{\mathbf{3}}\right) & 51,590\end{array}$

Berdasarkan Tabel 5, dapat dikatakan bahwa model terbaik adalah Model Regresi Binomial Negatif dengan Variabel Signifikan $x_{1}$ dan $x_{3}$. Hal ini dikarenakan nilai AIC Model Regresi Binomial Negatif denganVariabel Signifikan $x_{1}$ dan $x_{3}$ lebih kecil dari nilai AIC yang dihasilkan oleh model model Regresi Binomial Negatif, yaitu 51,590 < 54, 166 .

\section{KESIMPULAN}

Analisis regresi yang digunakan adalah Regresi Binomial Negatif karena terdapat asusmsi overdispersi pada data stunting di Kota Gorontalo Tahun 2018 dan setelah dianalisis menggunakan software RStudio didapatkan faktor-faktor signifikan yang mempengaruhi Stunting di Kota Gorontalo pada tahun 2018 adalah balita yang mendapatkan ASI ekslusif $\left(x_{1}\right)$ dan balita yang mendapatkan imunisasi dasar lengkap $\left(x_{3}\right)$. Hal ini ditunjukan dengan nilai $p$-value variabel balita yang mendapatkan asi eksklusif sebesar 0,00283 dan nilai $p$ value variabel balita yang mendapatkan imunisasi dasar lengkap sebesar 0,06564. Model Regersi Binomial negatif dengan Variabel Signifikan $x_{1}$ dan $x_{3}$ merupakan model terbaik dengan nilai AIC terkecil sebesar 51,59.

\section{DAFTAR PUSTAKA}

Alan Agresti (2009), An introduction to categorical data analysis (2nd edn)., John Wiley \& Sons, Inc., Hoboken, New Jersey. https://doi.org/10.1002/sim.3564.

Amaliana, L., Sa'adah, U., and Wardhani, N. W. S. (2018), "Performa Proporsi ZeroInflation Pada Regresi Zero-Inflated Negative Binomial (Studi Kasus: Data Tetanus Neonatorum Di Jawa Timur)," E-Jurnal Matematika, 7, 41. https://doi.org/10.24843/mtk.2018.v07.i01.p183.

Apriluana, G., and Fikawati, S. (2018), "Analisis Faktor-Faktor Risiko terhadap Kejadian Stunting pada Balita (0-59 Bulan) di Negara Berkembang dan Asia Tenggara," Media Penelitian dan Pengembangan Kesehatan, 28, 247-256.

https://doi.org/10.22435/mpk.v28i4.472.

Aulele, S. N. (2012), "Pemodelan Jumlah Kematian Bayi Di Provinsi Maluku Tahun 2010 Dengan Menggunakan Regresi Poisson,” BAREKENG: Jurnal Ilmu Matematika dan 
Terapan, 6, 23-27. https://doi.org/10.30598/barekengvol6iss2pp23-27.

Dhiya, A. Y. (2020), "Pemodelan Penderita Stroke dan Diabetes Melitus di Kota Padang dengan Model Regresi Logistik Biner Bivariat," IX, 270-277.

Fitrial, N. H., and Fatikhurrizqi, A. (2021), "Pemodelan Jumlah Kasus Covid-19 Di Indonesia Dengan Pendekatan Regresi Poisson Dan Regresi Binomial Negatif," Seminar Nasional Official Statistics, 2020, 65-72. https://doi.org/10.34123/semnasoffstat.v2020i1.465.

Herindrawati, A. Y., Latra, I. N., and Purhadi, P. (2017), "Pemodelan Regresi Poisson Inverse Gaussian Studi Kasus: Jumlah Kasus Baru HIV di Provinsi Jawa Tengah Tahun 2015," Jurnal Sains dan Seni ITS, 6. https://doi.org/10.12962/j23373520.v6i1.22976.

Keswari, N. M. R., Sumarjaya, I. W., and Suciptawaty, N. L. P. (2014), "Perbandingan Regresi Binomial Negatif dan Regresi Generalisasi Poisson dalam Mengatasi Overdispersi (Studi Kasus: Jumlah Tenaga Kerja Usaha Pencetak Genteng di Br. Dukuh, Desa Pejaten)," E-Jurnal Matematika, 3, 107. https://doi.org/10.24843/mtk.2014.v03.i03.p072.

Mahfudhotin, M. (2020), "Regresi Generalized Poisson Untuk Memodelkan Jumlah Penderita Gizi Buruk Pada Balita di Surabaya," Jambura Journal of Probability and Statistics, 1, 47-56. https://doi.org/10.34312/jjps.v1i1.6876.

Prahutama, A., Sudarno, Suparti, and Mukid, M. A. (2017), “Analisis Faktor-Faktor Yang Mempengaruhi Angka Kematian Bayi Di Jawa Tengah Menggunakan Regresi Generelized Poisson Dan Binomial Negatif," Statistika, 5, 1-6.

Ramadhani, N., Yanuar, F., and Yozza, H. (2018), "Penerapan Regresi Poisson Generalized Poisson Regression Dalam Memodelkan Kasus Angka Kematian Ibu Di Sumatera Barat Tahun 2015," Jurnal Matematika UNAND, 7, 112. https://doi.org/10.25077/jmu.7.2.112-117.2018.

Rochmad (2013), “Aplikasi Metode Newton-Raphson Untuk Menghampiri Solusi Persamaan Non Linear," Jurnal MIPA, 36, 193-200.

Sauddin, A., Auliah, N. I., and Alwi, W. (2020), "Pemodelan Jumlah Kematian Ibu di Provinsi Sulawesi Selatan Menggunakan Regresi Binomial Negatif," Jurnal MSA ( Matematika dan Statistika serta Aplikasinya ), 8, 42. https://doi.org/10.24252/msa.v8i2.17409.

Sma, S., Yang, S. M. K., Lulus, T., and Di, U. N. (2012), "Penerapan Regresi Poisson Untuk Mengetahui Faktor-Faktor Yang Memengaruhi Jumlah,” 1, 59-63.

Sundari, I. (2012), "Regresi Poisson dan Penerapannya Untuk Memodelkan Hubungan Usia dan Perilaku Merokok Terhadap Jumlah Kematian Penderita Penyakit Kanker Paru-Paru," Jurnal Matematika UNAND, 1, 71. https://doi.org/10.25077/jmu.1.1.7176.2012.

Utami, T. W. (2013), “Analisis regresi binomial negatif untuk mengatasi overdispersion regresi poisson pada kasus demam berdarah dengue," Jurnal Statistika Universitas Muhammadiyah Semarang, 1, 0-6. 